New diseases

\title{
The andropause: fact or fiction?
}

\author{
Nicholas Burns-Cox, Clive Gingell
}

\section{Summary}

The so-called andropause is an illdefined collection of symptoms in a group of men who may have low but may also have normal androgen levels. Unlike the proven benefits of hormone replacement therapy in women, the effects of testosterone supplementation in men are equivocal. It may increase sexual interest, but rarely to a level thought adequate by the patient. It has no proven beneficial effect on erectile dysfunction and other possible beneficial effects on haemopoesis, bone metabolism, lipids and fibrinolysis have yet to be demonstrated. With the availability of the testosterone patch, sustained increases in the serum testosterone levels will be readily achieved and could theoretically significantly affect the behaviour of subclinical prostate cancer. At the present time, testosterone replacement therapy in hypogonadal men is of proven clinical benefit; this is not the case, however, for eugonadal men with symptoms attributed to the andropause. The symptoms of the andropause fatigue can readily be explained by stress and there is no scientifically valid, placebocontrolled study that shows any benefit for testosterone supplements in this not uncommon group of patients.

Keywords: andropause, testosterone supplements, prostate cancer, erectile dysfunction

Bristol Urological Institute, Southmead Hospital, Bristol BS10 5NB, UK

N Burns-Cox

C Gingell

Correspondence to $\mathrm{Mr} \mathrm{C}$ Gingell

Accepted 21 August 1996
The menopause is a condition with a proven pathophysiological aetiology, leading in some women to unpleasant symptoms and bone loss over the ensuing years. The relatively sudden onset of ovarian failure causes amenorrhoea, infertility and oestrogen deficiency. There is no analogous process in the male. However, the term andropause is being increasingly used to describe a collection of symptoms including lack of energy, depression, decreased libido and erectile difficulties occuring in middle-aged or elderly men with a testosterone level at the lower end of normal range. The term andropause, like menopause, implies a state of hormone deficiency secondary to gonadal failure and the similarity of the two terms tends to give the andropause some unproven credibility. The incidence of erectile dysfunction increases with age and it is tempting to correlate this with the relative decrease in testosterone seen with age. It is therefore likely that androgen supplementation will be used to try and boost testosterone levels in middle-aged men with erectile difficulties who are not hypogonadal. There is, however, no evidence that the increase in erectile difficulties with age is related to decreasing testosterone levels in these eugonadal men. In this article we review the action of testosterone, the changes that occur with aging and the likely benefits and risks of supplementation.

\section{Androgen production and aging}

Testosterone is a C19 steroid and $0.24 \mu \mathrm{mol} /$ day are secreted by the Leydig cells of the testicle. ${ }^{1}$ Its production is regulated by a negative feedback loop involving luteinising hormone and luteinising hormone-releasing hormone (LHRH), and forming the hypothalamic-pituitary-gonadal axis. Androgens are also secreted by the adrenal cortex in men $(0.002 \mu \mathrm{mol} / \mathrm{day})$, mainly as androstenedione but the quantities are of little clinical significance in comparison with the amount secreted by the testes. Testosterone is metabolised by the action of 5-alpha-reductase to to the biologically active androgen dihydrotestosterone and by aromatase activity to oestradiol. Secretion of testosterone begins in the foetus with a peak in the male at 12 weeks. There is another peak after birth and a low level equal to the female remains until puberty. At puberty increased pulsatile secretion of luteinising hormone leads to maturation of the Leydig cells and hence to increased testosterone production.

The action of the testosterone is firstly androgenic leading to the secondary sexual characteristics of the adult male. It also has an anabolic effect on receptive tissue leading to increased muscle bulk. The great majority of testosterone $(80 \%)$ is bound to sex-hormone-binding globulin (SHBG) and to a lesser degree to albumin and cortisol-binding globulin. Only about $2 \%$ of total testosterone remains free, and it is this free portion that is thought to be of biological importance. ${ }^{2}$ There is debate as to which fractions are bioavailable ${ }^{3-4}$ but it is generally considered that the non-SHBG bound fraction is biologically active. The other measure of bioavailability is the Androgen Index which is the ratio of total testosterone to SHBG multiplied by 100 , and is comparable to the free testosterone concentration. ${ }^{2}$ In males, there is a progressive decrease in testosterone levels with age ${ }^{5-7}$ (table 1 ). However, there is a concurrent increase in SHBG and therefore a greater decrease in the concentration of the free testosterone ${ }^{8-10}$ which is reported to fall at a rate of $1 \%$ per year. The levels of dihydrotestosterone responsible for many of the actions of testosterone at the cellular level do not show a decrease with age. ${ }^{8}$ Although the decrease in testosterone is seen in healthy elderly men, ${ }^{11}$ a greater decrease in testosterone is seen in people with concomitant illnesses, ${ }^{12}$ which are very common in this age group.

There is evidence for some degree of testicular failure with advancing years. There is a decrease in the number of Leydig cells, ${ }^{13,14}$ impaired testicular perfusion, ${ }^{15}$ decreased steroid response to stimulation by beta-human chorionic gonadotropin, ${ }^{16,17}$ and a moderate rise in luteinising hormone levels. ${ }^{16}$ But there is also evidence that the decrease in testosterone is not all of primary testicular 
Table 1 Influence of age on plasma testosterone, free testosterone and SHBG levels in man

\begin{tabular}{lllll}
\hline & \multicolumn{3}{l}{ Testosterone (nmol) } & \\
\cline { 2 - 4 } Age (years) & $n$ & Plasma & Free & SHBG $\left(10^{-8} \mathrm{M}\right)$ \\
\hline $18-29$ & 105 & $23.1 \pm 6.8$ & $0.52 \pm 0.15$ & $4.2 \pm 1.2$ \\
$30-49$ & 30 & $21.4 \pm 7.3$ & $0.40 \pm 0.12$ & $4.5 \pm 1.4$ \\
$50-59$ & 24 & $17.0 \pm 8.0$ & $0.3 \pm 0.13$ & $5.5 \pm 1.3$ \\
$60-69$ & 63 & $16.3 \pm 6.6$ & $0.27 \pm 0.09$ & $6.0 \pm 1.4$ \\
$70-79$ & 63 & $16.5 \pm 7.3$ & $0.23 \pm 0.08$ & $7.3 \pm 1.8$ \\
$80-89$ & 60 & $15.0 \pm 5.7$ & $0.17 \pm 0.04$ & $7.3 \pm 2.0$ \\
\hline
\end{tabular}

By kind permission from A Vermeulen ${ }^{7}$

origin, the hypothalamic-pituitary-gonadal axis is also implicated. There is loss of the circadian rhythmicity of serum testosteron $\mathrm{e}^{18}$ and increased sensitivity to negative feedback by the sex hormones on gonadotropin secretion. ${ }^{19}$ However, although there is a decrease in both total and free testosterone with age, the decrease is gradual and levels do not fall outside the normal range. ${ }^{7}$

The variability between individuals is great and some elderly men have the same levels as young men, indicating that, unlike the ovary after the menopause, the testicle continues to secrete significant quantities of testosterone throughout life. In contrast to the post-menopausal ovary, the testicle continues gamete production and fertility persists life-long. Although a loss of fertility potential is not a typical finding in the elderly, with increasing age the sperm count is reduced due to a decrease in Sertoli cells ${ }^{15,20,21}$ and some decrease in motility is reported. ${ }^{12,22}$ Nevertheless, it seems that the zona-free hamster egg fertilizing capacity of the spermatozoa of elderly men is similar to that of young men. Although there is no sudden degeneration of the testicle analogous to that of the ovary, there is still a definite progressive decrease in the ability of the testes to produce spermatozoa and testosterone. The reduction of fertility in the elderly male rarely becomes of clinical significance. The decrease in testosterone secretion, however, is thought by some clinicians to be responsible for a group of symptoms ascribed to the andropause. These include nervousness, insomnia, hot flushes, mental and physical tiredness, irritability, reduced libido and erectile dysfunction. There are age-related changes, including decreased muscle mass and body hair, and disturbance of bone density and haemopoesis ${ }^{7}$ have also been described as being due to testosterone deficiency.

\section{Hormone replacement and supplements}

The case for hormone replacement in men and children who are truly hypogonadal is generally accepted as beneficial. ${ }^{23-25}$ There are a variety of types and modes of administration of testosterone. The currently available compounds for androgen replacement are shown in table 2 . Some of the early oral preparations (eg, methyltestosterone and Danazol) are alkylated at the 17-

Table 2 Summary of the current available testosterone compounds for androgen replacement

\begin{tabular}{|c|c|c|c|c|}
\hline $\begin{array}{l}\text { Type of } \\
\text { testosterone }\end{array}$ & $\begin{array}{l}\text { Name } \\
\text { (Trade name) }\end{array}$ & $\begin{array}{l}\text { Route of } \\
\text { administration }\end{array}$ & Dose (mg) & Frequency \\
\hline \multirow[t]{3}{*}{ Testosterone esters } & $\begin{array}{l}\text { Testosterone } \\
\text { undeconoate } \\
\text { (Restandol) }\end{array}$ & oral capsules & $\begin{array}{l}40-120 \\
25 \\
40\end{array}$ & once daily \\
\hline & Mesterolone & oral & & $\begin{array}{l}3-4 \text { times a day, } \\
\text { reduced for } \\
\text { maintenance }\end{array}$ \\
\hline & $\begin{array}{l}\text { Testosterone } \\
\text { propionate } \\
\text { (Sustanon) }\end{array}$ & $\begin{array}{l}\text { intramuscular } \\
\text { injection }\end{array}$ & 40 & every 2 weeks \\
\hline Testosterone & - & implant & 600 & 6-monthly \\
\hline Testosterone & (Testop) & $\begin{array}{l}\text { transdermal on } \\
\text { scrotal skin only }\end{array}$ & 3.6 & once daily \\
\hline Testosterone & (Andropatch) & $\begin{array}{l}\text { transdermal } \\
\text { patch placed on } \\
\text { any skin which } \\
\text { does not cover a } \\
\text { bony prominence }\end{array}$ & 2.5 & once daily \\
\hline
\end{tabular}


hydroxy position, making the androgen more resistant to hepatic metabolism. However, these oral preparations often give unpredictable serum levels of testosterone and are more likely to cause side-effects, including cholestatic jaundice, and can rarely lead to hepatic failure (haemorrhagic liver cysts) ${ }^{26}$ For these reasons they are no longer available in the UK for androgen replacement. Alternatively, testosterone can be esterified and given as an oral agent daily (eg, mesterolone), a depot injection (eg, testosterone propionate) every two weeks or as a surgically implanted pellet every six months. These result in a sustained level of plasma testosterone. The availability of testosterone patches in the UK will provide a more physiological and 'user friendly' delivery system for patients requiring androgen replacement therapy and has been shown to be very effective. ${ }^{27}$

Support for hormone supplementation comes from trials on men who have moderately low age-related levels of testosterone. Potentially advantageous increases in lean body mass and insulin sensitivity have been shown, ${ }^{28,29}$ as have increases in fibrinolytic activity. ${ }^{31,32}$ Androgens have been shown to affect the balance of blood lipids. Men generally have lower levels of high-density lipoproteins (HDLs) and higher levels of low density liproteins (LDLs) than premenopausal women and the administration of testosterone in hypogondal men further decreases the HDL levels. However, the type of testosterone administered determines the effect on lipids. The orally active 17-alkylated testosterone preparations cause a markedly lower HDL concentration and raised LDL concentration; this is not seen with the parenterally administered testosterone esters. ${ }^{32}$ Indeed, Tenover et al reported an $11 \%$ decrease in LDL with testosterone ester supplementation; the significance of this finding for cardiovascular disease is unclear, however. ${ }^{33}$ Conversely there have been reports of associations between low testosterone and increased adiposity, ${ }^{34}$ insulin resistance, ${ }^{35}$ low fibrinolytic activity, ${ }^{36}$ and coronary artery stenosis. ${ }^{37}$ The importance of these associations is unclear. Some authors consider that the low testosterone may be the result of ill health and not a contributing factor to it. ${ }^{7,12}$ The effect of aging on sexual function and its relationship to androgen production is difficult to quantify. Certainly there is a decrease in sexual activity with age but many factors are involved, including psychological (eg, fear of failure, boredom with partner) and organic (eg, decreased penile sensation and impaired blood supply to the penis) ones. ${ }^{7}$ Korenman et al showed that the levels of both testosterone and gonadotropin are similar in potent and impotent elderly men. ${ }^{38}$ Both groups show an impaired response to LHRH stimulation as compared with younger men. The authors concluded that hormonal changes and impotence were two independent conditions in older men.

Individuals complaining of decreased well-being, loss of sexual interest and erectile difficulties have symptoms that are common, nonspecific and frequently associated with stress. It has been reported that well-being and sexual interest can be increased by testosterone supplements. ${ }^{33,39,40}$ However, of the 10 men who objectively showed a small improvement, only three felt that the therapy was adequate. ${ }^{40}$ There is also clinical evidence from trials that androgen supplementation has no beneficial effect in men with erectile dysfunction who are eugonadal. ${ }^{40-42}$ With regard to erectile dysfunction, there is evidence that the normal process is androgen-independent. Hypogonadal men have been shown to have a normal erectile response to erotic stimuli. ${ }^{43,44}$ Further, a group of sexual offenders on the anti-androgen cyproterone acetate showed no decreased erectile response when shown erotic films. ${ }^{45}$ There is little evidence to date to support the concept that androgen supplements in eugonadal men are of any significant benefit.

\section{The role of testosterone in prostate cancer}

It is known that prostatic cancer is androgen-dependent and that the principal therapy of advanced disease is the removal of androgen stimulation. ${ }^{46}$ This is achieved by medical or surgical castration or the administration of antiandrogen, alone or in combination, so-called maximum androgen blockade. ${ }^{47} \mathrm{It}$ is likely therefore that the administration of androgen to a man with prostate cancer will stimulate activity in what is mainly a hormone-dependent tumour. Certainly in the first 10-12 days after the administration of an LHRH analogue the serum testosterone rises and so-called 'tumour flare' results, in which bony metastases become more painful, paraplegia may be precipitated, and ureteric obstruction may occur. ${ }^{48}$ It is therefore likely that giving testosterone to men with latent cancer within the prostate may promote the development of active clinically evident disease. It is consequently of paramount importance to check the plasma prostate-specific antigen (PSA) level before the administration of testosterone to any man greater than 50 years and to check this regularly on 


\section{Summary points}

- testicular failure analagous to menopausal ovarian failure does not occur

- testosterone supplementation has no proven role in the treatment of erectile dysfunction in patients with a normal testosterone level

- the risks of stimulating subclinical hormone sensitive prostate cancer is unknown but credible

- men over 60 years starting testosterone supplementation should have a transrectal ultrasound and biopsy and then be followed up with regular serum PSA levels

treatment. Unfortunately, there is no clear cut-off point, but a rising PSA on treatment should arouse suspicion. In a study of 33 men with low serum levels of free or total testosterone aged 45-75 years, with normal age-adjusted PSA levels and negative digital rectal examination, transrectal ultrasound-guided biopsies of the prostate were undertaken. ${ }^{49} \mathrm{Six}(18 \%)$ were discovered to have cancer, five of whom were aged between 62 and 65 years old with a PSA of less than $3 \mathrm{ng} / \mathrm{l}$. These results raise serious concerns about the use of androgen therapy in men over 60 years old. The authors speculated that low androgen levels may have falsely lowered the PSA into the normal range in some of these men. They concluded that prostatic biopsy should be mandatory prior to testosterone therapy in men over 60 years old and strongly encouraged in men between 50 and 59 years old.

\section{Conclusion}

Evidence-based medicine demands that the extent of the risks be known and the benefits quantified by controlled trials. The symptoms of fatigue (mental and physical), loss of energy, depression and decreased libido which constitute the so-called andropause, can readily be explained by stress and there is no convincing, scientifically valid, placebo-controlled study that shows any benefit for testosterone supplements in these patients.

20 Mineau GP, Trussel L. A specification of marital fertility by parent's age at marriage and marital duration. Demography 1982; 19: 335-49.

1 Jeffcoate SL, Brocks RV, Lin NY, London DR. Endocrinol 1967; 37: 401 hyp

2 Wheeler MJ. Determination of bio-available testerone. Ann Clin Biochem 1995; 32: 345 57.

57.

Ekins R. Measurement of free hormones in blood. Endocrinol Rev 1990; 11: 5-46.

4 Meikel CM. The free hormone hypothesis: a physiologically based mathematical model. Endocrinol Rev 1989; 10: 232-74.

5 Hollander M, Hollander Y. The microdetermination of the testosterone in the human spermatic vein. 7 Clin Endrocrinol Metab 1958; 18 : 966-70.

6 Kent JZ, Acone AB. Plasma testosterone levels and aging in males. In: Vermeulen A, Exley $D$, eds. Androgens in normal and pathological conditions. Int Congr Series, 1966, no 101:31-5.

7 Vermeulen A. The male climacterium. Ann Med 1993; 25: 531 - 4 .

8 Gray A, Feldman HA, McKinlay JB, Longcope C. Age, disease and changing sex hormone levels in middle aged men: results of the Massachusetts male aging study. F Clin Endocrinol Metab 1991 . 73. $1016-25$.

9 Nahoul K, Rayer M. Age-related decline of plasma available testosterone in adult men. $f$ Steroid Biochem 1990; 35: 293 -9.

10 Purifoy FE, Koopmans LH, Mayes DM. Age differences in serum androgen levels in norma adult males. Hum Biol 1981; 53: 499-511.

11 Vermeulen A. Androgens and male senescence. In: Nieschlag E, Behre HM, eds, Testosterone: action, deficiency, substitution. Berlin: Springer action, deficiency, substitution.
Verlag, 1990; pp 261-73.

12 Nieschlag E, Lammers U, Frieischem CW, Langer K, Wickings EJ. Reproductive function in young fathers and Reproductive function in young fathers and grandfather.

13 Sniffen RC. The testis. The normal testis. Arch Pathol 1950; 50: 259-84

14 Neaves WB, Johnson L, Porter JC, Parker CR, Petty CS. Leydig cell numbers, daily sperm production and serum gonadotrophin levels in aging men. F Clin Endocrinol Metab 1984; 59: $756-63$

15 Sesano $M$, Ishyo S. Vascular patterns of the human testes with special reference to senile
changes. Tohaku $\mathcal{F}$ Exp Med 1969; 99: 269-80.

16 Rubens R, Dhont M, Vermeulen A. Further studies on Leydig cell function in old age. J Clin Endocrinol Metab 1974; 39: 40-5.

17 Mankin HR, Lin T, Muruno EP, Osterman J. The aging Leydig cell: III Gonadotrophin stimulation in men. F Androl 1981; 2: 181-9.

18 Bremner WJ, Vitello M, Prinz PN. Loss of circadian rythmicity in blood testosterone levels with aging in normal men. $\mathcal{F}$ Clin Endocrinol Metab 1983; 56: $1278-81$.

19 Winters SJ, Sherins RJ, Truen P. The gonadotrophin suppressible activity of androgens is increased in elderly men. Metabolism 1984; 33: $1052-9$
21 Johnson L. Spermatogenesis and aging in humans. F Androl 1986; 7: 331-54.

22 Schwartz D, Mayaux MJ, Spira A, et al. Semen characteristics as a function of age in 833 fertile men. Fertil Steril 1983; 39: 530-5.

23 Davidson JM, Camargo C, Smith ER. Effects of androgens on sexual behavior in hypogonadal men. $\mathcal{F}$ Clin Endocrinol Metab 1979; 48: 955-8.

24 Skalkebaek M, Bancroft J, Davidson D, Warne $P$. Androgen replacement with oral testosterone undeconoate in hypognadal men: a double blind controlled study. Clin Endocrinol 1981; 14: 4961.

25 Luisi M, Franchi F. Double blind group comparative study of testosterone undeconoate and mesteronone in hypogonadal male patients. f Endocrinol Invest 1980; 3: 305-8.

26 Ishak KG, Zimmerman HJ. Hepatotoxic effects of the anabolic/androgenic steroids. Semin Liver Dis 1987; 7: 230-6.

27 Meikle AW, Mazer MA, Moellmer JF, et al. Enhanced transdermal delivery of testosterone across scrotal skin produces physiological concentrations of testosterone and its metabolites in hypogonadal men. $\mathcal{F}$ Clin Endocrinol Metab 1992; 74: $122-5$.

28 Marin P, Krotkiewski M, Bjorntorp P. Androgen treatment of middle aged obese men: effects on metabolism, muscle and adipose tissue. Eur $\mathcal{F}$ Med 1992; 1: $329-36$.

29 Forbes GB, Porta CR, Herr BE, Griggs RC. Sequence of changes in body composition induced by testosterone and reversal of changes after drug is stopped. $\mathcal{A} A M A$ 1992; 267: $397-9$.

30 Walker ID, Davidson JF. Long term fibrinolytic enhancement with anabolic steroid therapy: A five year study. In: Davidson JF, Rowan RM, Samama MM, Desnoyers PC, eds. Progress in chemical fibrinolysis and thrombolysis, vol 3 . New York: Raven Press, 1978; pp 491-9.

31 Fearnley GR, Chakrabarti R. Increase of blood fibrinolytic activity by testosterone. Lancet 1962; 2: $128-32$.

32 Bardin CW, Swerdloff RS, Santen RJ. Androgens: risks and benefits. $\mathcal{f}$ Clin Endocrinol Metab 1991; 73: 4-7.

33 Tenover JS. Effects of testosterone supplementation in the aging male. $\mathcal{F}$ Clin Endocrinol Metab

34 Khaw KT, Barrett-Connor E. Lower endogenous androgens predict central a diposity in men. Ann Epidemiol 1992; 2: 675-82.

5 Simon Di Preziosi P, Barrett-Conner E, et al. Interrelation between plasma testosterone and plasma insulin in healthy adult men: the Telecom study. Diabetologia 1992; 35: 173-7.
36 Bonithon-Kopp C, Scarabin PY, Bara L, Castanier M, Jacqueson A, Roger M. Relationship between sex hormones and haemostatic factors in healthy adult men. Atherosclerosis 1988; 71: $71-6$.

37 Brier C, Muhlberger V, Drexel H, et al. Essential role of post heparin lipoprotein lipase activity and of plasma testosterone in coronary artery disease. Lancet 1985; 1: 1339 .

38 Korenman SG, Morley JE, Mooradian AD, et al. Secondary hypogonadism in older men: it's relation to impotence. F Clin Endocrinol Metab 1990; 71: $963-9$.

39 Matsumato AM. Effects of chromic testosterone administration in normal men: safety and efficacy of high dosage testosterone and parallel dose dependent suppression of luteinizing hormone, follicle sumulating hormenizing horproduction. f Clin Endocrinol Metab 1990; 70: $282-7$.

40 O'Carrol R, Bancroft J. Testosterone therapy for low sexual interest and erectile dysfunction in men: a controlled study. $B r \mathcal{F}$ Psychiatry 1984; 145: $146-51$.

41 Cooper AJ. A clinical and endocrine study mesterolone in secondary impotence. $\mathcal{F}$ Psychosom Res 1980; 24: 275-9.

42 Benkert O, Witt W, Adam W, Leitz A. Effects of testosterone undeconoate on sexual potency and the hypothalamic-pituitary-gonadal axis of impotent men. Arch Sexual Behav 1979; 8: 471-9.

43 Bancroft J, Wu FC. Changes in erectile responsiveness during androgen replacement therapy. Arch Sexual Behav 1983; 12: 59-66.

44 Kwan M, Greenleaf WJ, Mann J, Crapo L, Davidson JM. The nature of androgen action on male sexuality: a combined laboratory self report study on hypogonadal men. F Clin Endocrinol Metab 1983; 57: 557-62.

5 Bancroft J, Tennent T, Loucas K, Cass J. Control of deviant sexual behavior by drugs: behavioral effects of oestrogens and antiandrogens. Br $\mathcal{F}$ Psychiatry 1974; 125: 310-5.

46 Huggins C, Stevens RE Jr, Hodges CV. Studies on prostatic cancer 11 . The effects of castration on advanced carcinoma of the prostate gland. Arch Surg 1941; 43: 208-23.

47 Labrie F, Dupont A, Belanger A, et al. A new approach in the treatment of prostate cancer: complete instead of partial withdrawal of androcomplete instead of partial withd

48 Waxman J, Man A, Hendry WF. Importance of early tumour exacerbation in patients treated with long acting analogues of gonadotrophn releasing hormone for advanced prostatic cancer. $B M F$ 1985; 291: $1387-8$

49 Bruning CO, III, DeWolf WC, Mongentaler A. Occult prostate cancer in hypogonadal men prior to testosterone therapy. $\mathcal{F}$ Urol 1995; 153: abstract 407 . 